\title{
Is Next Twelve Months Period Tumor Recurrence Free Under Restricted Rate Due to Medication? A Probabilistic Warning
}

Ramalingam Shanmugam

Texas State University,rs25@txstate.edu

Follow this and additional works at: http://digitalcommons.wayne.edu/jmasm

Part of the Applied Statistics Commons, Social and Behavioral Sciences Commons, and the Statistical Theory Commons

\section{Recommended Citation}

Shanmugam, Ramalingam (2011) "Is Next Twelve Months Period Tumor Recurrence Free Under Restricted Rate Due to Medication? A Probabilistic Warning," Journal of Modern Applied Statistical Methods: Vol. 10 : Iss. 1 , Article 30.

DOI: $10.22237 /$ jmasm/1304224140

Available at: http://digitalcommons.wayne.edu/jmasm/vol10/iss1/30 


\title{
Is Next Twelve Months Period Tumor Recurrence Free Under Restricted Rate Due to Medication? A Probabilistic Warning
}

\author{
Ramalingam Shanmugam \\ Texas State University, \\ San Marcos, TX USA
}

\begin{abstract}
A methodology is formulated to analyze tumor recurrence data when its incidence rate is restricted due to medication. Analytic results are derived to make a probabilistic early warning of tumor recurrence free period of length $\tau$; that is, the chance for a safe period of length $\tau$ is estimated. The captured data are length biased. Expressions are developed to extract and relate to counterparts of the non-length biased data. Three data sets are considered as illustrations: (1) patients who are given a placebo, (2) patients who are given the medicine pyridoxine and (3) patients who are given the medicine thiotepa.
\end{abstract}

Key words: Targeted versus captured recurrence trend, order statistics, survival function.

\section{Introduction}

Cancer is the second major cause of death after cardiovascular deaths in USA. Tumor, an abnormal growing of cells in the brain, is an important category in the cancer group and remains mysterious to medical researchers. Whether a tumor is a benign or malignant type, its recurrence time must be speculated for an efficient treatment and an early warning of its recurrence time is crucial. The early warning provides a basis for the decision of whether to continue the same medicine or change to another medicine. The medical community relies heavily on an answer to the question: what do the data suggest? The statistical community is obligated to devise an appropriate statistical methodology to analyze a patient's data to make a probabilistic early warning regarding whether a time period of length $\tau$ will be tumor recurrence free.

Ramalingam Shanmugam is a Professor in the School of Health Administration. His research interests include multivariate data modeling, informatics, optimal decision support systems, and health/medical application of statistics. Email him at: rs25@txstate.edu.
The current literature does not contain information to answer these questions. To compensate for the gaps in this area, this study was undertaken to introduce a new statistical methodology to fulfill the need for making an early probabilistic warning of tumor recurrence during a tumor free period of length $\tau$.

Let $T>0$ represent a random time in which a tumor (malignant or benign) reoccurs in a patient. Given the collected data on his/her recurrence times, could a future period of length $\tau$ be tumor recurrence free? Suppose that the uncertainty in $\mathrm{T}$ is governed by non-observable incidence parameters $\theta<\beta$, where $\theta$ and $\beta$ portray the tumor recurrence rate and its restriction level respectively. A restriction on the incidence rate exists due to the effect of the given medication. Let $v>0$ be the threshold time parameter connecting $\mathrm{T}, \theta$ and $\beta$. To capture their intricacies, consider the probability density function:

$$
\begin{aligned}
& f_{\text {tumor }}^{\text {targ } \text { eted }}(t \mid \beta, \theta, v)=\left(\frac{\beta}{\theta}-1\right) \phi^{\frac{\beta}{\theta}-1} /(t+\phi-v)^{\frac{\beta}{\theta}} \\
& t>v ; 0<\theta<\beta
\end{aligned}
$$

for $\mathrm{T}>v>0$ in terms of $\theta$ and $\beta$. The expected and variance time of the probability pattern in (1) are, respectively, 


$$
\begin{aligned}
\mu_{\text {tumor }}^{t \text { arg eted }}(t \mid \beta, \theta, v) & = \\
& =E(t \mid \beta, \theta, v) \\
& =\frac{\phi}{\frac{\beta}{\theta}-2}+v
\end{aligned}
$$

and

$$
\begin{aligned}
\sigma_{\text {tumor }}^{2, t \text { arg eted }}(t \mid \beta, \theta, v) & = \\
& =\operatorname{Var}(t \mid \beta, \theta, v) \\
& =\left(\frac{\phi+\mu_{\text {tumor }}^{\text {targ eted }}}{\phi-\mu_{\text {tumor }}^{\text {arg } \text { eted }}}\right)\left(\mu_{\text {tumor }}^{t \text { arg eted }}\right)^{2}
\end{aligned}
$$

A recurrence is missed if the observation period is too short; a longer observation period increases the chance of recording another tumor recurrence. This concept is length biased sampling (see Zelen \& Feinlieb, 1969 for details on length bias phenomenon). The length bias alters the statistical assessment of the recurrence trend. A caution is necessary regarding how the lengthbiased data are analyzed and interpreted. When the equal random sampling is replaced by proportional length biased sampling, the lengthbiased version of the model in (1) is appropriate for the recurrent tumor times as follows:

$$
\begin{aligned}
f_{\text {tumor }}^{\text {captured }}(t \mid \beta, \theta, v) & = \\
& =\frac{t f_{\text {tumor }}^{t \text { arg eted }}(t \mid \beta, \theta, v)}{\mu_{\text {tumor }}^{\text {targeted }}(t \mid \beta, \theta, v)} t \\
& =\frac{t\left(\frac{\beta}{\theta}-1\right) \phi^{\frac{\beta}{\theta}-1}}{\left[\frac{\phi}{\left(\frac{\beta}{\theta}-2\right)}+v\right](t+\phi-v)^{\frac{\beta}{\theta}}} ; \\
t & >v ; 0<\theta<\beta
\end{aligned}
$$

where $\mu_{\text {tumor }}^{\text {targeted }}$ denotes the actual average tumor recurrence time. The probability density functions in (1) and (4) are interrelated and their relations are used to forecast tumor recurrence in this study by employing a methodology to analyze tumor recurrence data when its rate is restricted due to medication. Using the analytic results, an early warning of the next tumor recurrence free period of length $\tau$ is made. Various pertinent information in the lengthbiased data are extracted and compared to their counterparts under non-biased data.

\section{Results}

To identify whether a tumor recurrence free period of length $\tau$ exists at the earliest time possible, understanding its patterns is prerequisite. Since the last major tumor recurrence, the probability that a next recurrence will happen within a selected time $\tau>0$ is

$$
\begin{aligned}
F_{\text {tumor }}^{\text {captured }}(\tau) & = \\
& =\operatorname{Pr}_{\text {tumor }}^{\text {captured }}(t \leq \tau)=1-S_{\text {tumor }}^{\text {captured }}(\tau) \\
& =1-\left(\frac{\phi}{\tau+\phi-v}\right)^{\frac{\beta}{\theta}-1}\left[1+\left(\frac{\beta}{\theta}-1\right)\left(\frac{\tau-v}{\phi}\right)\right] \\
& =F_{\text {tumor }}^{\text {int ended }}(\tau-v) \\
& -\left(\frac{\beta}{\theta}-1\right)\left(\frac{\tau-v}{\phi}\right)\left[1-F_{\text {tumor }}^{\text {int ended }}(\tau-v)\right] .
\end{aligned}
$$

The actual chance for tumor recurrence occurs within $\tau$ units of time and requires an adjustment of the captured chance for tumor recurrence time. This is revealed in the relationship shown in (5); the adjustment is

$$
F_{\text {tumor }}^{\text {int ended }}(\tau-v)=\frac{F_{\text {tumor }}^{\text {captured }}(\tau-v)+\left(\frac{\beta}{\theta}-1\right)\left(\frac{\tau-v}{\phi}\right)}{1+\left(\frac{\beta}{\theta}-1\right)\left(\frac{\tau-v}{\phi}\right)} .
$$

In an instantaneous time (that is, $\tau \rightarrow v$ ), no adjustment is necessary, but after some time has elapsed, a finite amount of adjustment is necessary. Both a location shift and a scale change are warranted. The location and scale shifts are

$$
\left(\frac{\beta}{\theta}-1\right)\left(\frac{\tau-v}{\phi}\right)
$$

and 


$$
1+\left(\frac{\beta}{\theta}-1\right)\left(\frac{\tau-v}{\phi}\right)
$$

respectively.

The captured survival chance without a tumor recurrence, that is

$$
\left.S_{\text {tumor }}^{\text {captured }}(\tau)=\operatorname{Pr}_{\text {captured }}[t>\tau]\right)
$$

with the length-biased data is

$$
1+\left(\frac{\beta}{\theta}-1\right)\left(\frac{\tau-v}{\phi}\right)
$$

times the actual survival chance, which is

$$
S_{\text {tumor }}^{\text {intended }}(\tau)=\operatorname{Pr}_{\text {intended }}[t>\tau]
$$

in a non-length biased data collection scenario without a tumor recurrence before that selected time $\tau$. That is,

$$
S_{\text {tumo }}^{\text {int ended }}(\tau)=\left[\frac{\theta \phi}{\theta \phi+(\beta-\theta)(\tau-v)}\right] S_{\text {tumor }}^{\text {captured }}(\tau)
$$

The cofactor

$$
\left[\frac{\theta \phi}{\theta \phi+(\beta-\theta)(\tau-v)}\right]
$$

is the impact amount due to sampling bias. The captured survivability chance without a tumor recurrence before that selected time $\tau$ is an over-estimate. The mean and variance time of the captured tumor recurrence patterns are expressed in terms of the actual average time $\mu_{\text {intended }}$ between two tumor recurrences. They are

$$
\begin{aligned}
\mu_{\text {tumor }}^{\text {captured }} & = \\
& =\int_{0}^{\infty} t f_{\text {tumor }}^{\text {captured }}(t) d t \\
& =2 \phi \mu_{\text {tumor }}^{\text {int ended }} /\left(\phi-\mu_{\text {tumor }}^{\text {int ended }}\right)
\end{aligned}
$$

and

$$
\begin{aligned}
\sigma_{\text {tumor }}^{2, \text { captuured }} & = \\
& =V a r_{\text {captured }}(t) \\
& =\int_{0}^{\infty}\left(t-\mu_{\text {tumor }}^{\text {captured }}\right)^{2} f_{\text {tumor }}^{\text {captured }}(t) d t \\
& =\frac{2 \phi^{2} \mu_{\text {tumor }}^{2, \text { int ended }}}{\left(\phi-\mu_{\text {tumor }}^{\text {int ended }}\right)\left(\phi-2 \mu_{\text {tumor }}^{\text {int ended }}\right)}
\end{aligned}
$$

$$
\text { if } \phi>2 \mu_{\text {tumor }}^{\text {intended }} \text {. }
$$

Expression (7) suggests a relation between the actual average tumor recurrence time $\mu_{\text {tumor }}^{\text {intended }}$ and the captured average tumor recurrence time $\mu_{\text {tumor }}^{\text {captured }}$. Equivalently,

$$
\mu_{\text {tumor }}^{\text {intended }}=\frac{\phi \mu_{\text {tumor }}^{\text {captured }}}{\left(2 \phi+\mu_{\text {tumor }}^{\text {captured }}\right)}
$$

The actual average tumor recurrence time is not linear with the captured recurrence time. Interestingly, according to expression (8), the captured variance of the recurrence times widens if the actual average tumor recurrence time is greater. Equivalently,

$$
\begin{aligned}
\sigma_{\text {tumor }}^{2, \text { int ended }} & = \\
& =\frac{1}{3}\left(1-\frac{2 \mu_{\text {tumor }}^{\text {int ended }}}{\phi}\right) \\
& {\left[\sigma_{\text {tumor }}^{2, \text { captuured }}+\frac{4 \phi^{2} \mu_{\text {tumor }}^{2, \text { int end }}}{\left(\phi-\mu_{\text {tumor }}^{\text {int ended }}\right)^{2}}\right] } \\
& -\mu_{\text {tumor }}^{2, \text { int ended }}
\end{aligned}
$$

meaning that the actual tumor occurrence time variance increases proportionally with the captured variance.

Based on this, the incidence parameters of the tumor recurrence probability pattern in (4) are estimable with $t_{(1)}=\min \left(t_{1}, t_{2}, \ldots t_{n}\right)$, $s_{\text {tumor }}^{2, \text { captured }}$ and $\bar{t}_{\text {tumor }}^{\text {captured }}-t_{(1)}$ denoting the captured threshold recurrence time, sample 
variance and mean of the tumor recurrence times respectively. The moment estimates are

$$
\begin{gathered}
\hat{v}=t_{(1)} \\
\hat{\phi}= \\
\frac{\left[\bar{t}_{\text {tumor }}^{\text {captured }}-t_{(1)}\right]\left[s_{\text {tumor }}^{2, \text { captured }}+\left(\bar{t}_{\text {tumor }}^{\text {captured }}-t_{(1)}\right)^{2}\right]}{\left|s_{\text {tumor }}^{2, \text { captured }}-2\left(\bar{t}_{\text {tumor }}^{\text {captured }}-t_{(1)}\right)^{2}\right|},
\end{gathered}
$$

and

$$
\hat{\beta}=\left\{2+\frac{3\left[\bar{t}_{\text {tumor }}^{\text {captured }}-t_{(1)}\right]^{2}}{\left|s_{\text {tumor }}^{2, \text { captured }}-2\left(\bar{t}_{\text {tumor }}^{\text {captured }}-t_{(1)}\right)^{2}\right|}\right\} \theta
$$

Thus, with estimates for (9), (10) and (11), the survival probability in (6) is estimable. When $1-\hat{S}_{\text {tumor }}^{\text {captured }}(\tau)$ is significantly large, it suggests that early warning is necessary to speculate whether the tumor recurrence is likely to happen within the selected time $\tau$. In addition, the factor

Restriction $=\left\{1+\frac{3\left[\bar{t}_{\text {tumor }}^{\text {captured }}-t_{(1)}\right]^{2}}{\left|s_{\text {tumor }}^{2, \text { captured }}-2\left(\bar{t}_{\text {tumor }}^{\text {captured }}-t_{(1)}\right)^{2}\right|}\right\}$

signifies the restriction level on tumor recurrence due to medication.

Often the likelihood of noticing a quick tumor recurrence if it occurs repeatedly is of interest. This can be accomplished using the order statistics concept (see David, 2005 for details regarding order statistics definitions and tools). Suppose that tumor reoccurrence takes place $n$ times for a patient and let the order statistics be

$$
v \leq T_{(1)}<T_{(2)}<\ldots<T_{(n)}<\infty
$$

then

$$
\operatorname{Pr}^{\text {targ eted }}\left[T_{(1)}>\tau\right]=[1-F(\tau)]^{n}
$$

describes the chance of surviving a period of length $\tau$ without a tumor recurrence. Interestingly, it is observed that

$$
\begin{aligned}
\operatorname{Pr}^{\text {targ eted }}\left[T_{(1)}>\tau\right]= & \\
& =\left[\left(\frac{\phi}{\phi+\tau-v}\right)^{\frac{\beta}{\theta}-1}\right]^{n} \\
& =\left[\frac{\phi+\left(\frac{\beta}{\theta}-2\right) v}{\phi+\left(\frac{\beta}{\theta}-2\right) v+\tau-v}\right]^{n} \operatorname{Pr}^{\text {captured }}\left[T_{(1)}>\tau\right] .
\end{aligned}
$$

The factor

$$
\left[\frac{\phi+\left(\frac{\beta}{\theta}-2\right) v}{\phi+\left(\frac{\beta}{\theta}-2\right) v+\tau-v}\right],
$$

$\beta$

in (13) with a single incidence (that is, $n=1$ ), signifies the over-estimated proportion of the chance of having a minimal safe period $\tau$. This proportion of over-estimate diminishes as the patient experiences more recurrences (that is, as $n$ increases).

Examples

To illustrate results, tumor data from Andrews and Herzberg (1990) were selected, these data show placebo, pyridoxine drug and thiotepa drug groups. The mean and variance of tumor recurrence times are calculated for each patient along with the captured survivability for each patient using (5) and the cofactor using (6). (See Tables 1A, 2A and 3A.) For example, the patient with ID\# 13 in the placebo group has 0.71 captured chance of survivability without tumor recurrence in 12 months and the actual survivability chance is 0.03 times the captured chance of surviving without tumor recurrence.

Using expressions (9) through (11), the incidence parameters are estimated and are displayed in Tables 1B, $2 \mathrm{~B}$ and 3B. For example, the parameter estimates $\hat{\phi}$,

$$
\hat{v} \text { and the restriction gap (.) in }
$$
$\theta<(.) \beta$ on the incidence rate for patient \#13 in the placebo group are $0.53,2.14$ and 3 respectively; patient \#15 is an anomaly. Results 
presented in in Tables 1B, 2B and 3B also show the chance of a patient having a safe period without any tumor recurrence for the next twelve months is calculated using (13), and estimates for how much the over-estimation might have been in the length biased data are calculated using (14).

The restriction level in (12), location shift

$$
\left(\frac{\beta}{\theta}-1\right)\left(\frac{\tau-v}{\phi}\right)
$$

and scale shift

$$
1+\left(\frac{\beta}{\theta}-1\right)\left(\frac{\tau-v}{\phi}\right)
$$

due to length-biased sampling are calculated and displayed in Tables $1 \mathrm{~B}$ through $3 \mathrm{~B}$. For example, patient \#13 had 4.58, 19.2 and 20.2 as his/her restriction level for the incidence parameters, location and scale shifts due to length-biased sampling. Patient \# 13 is in the placebo group and has 0.03 chance of having a safe next twelve months without any tumor recurrence. If the length biased captured data are used for this patient, the chance of having safe next twelve months without any tumor recurrence would have been over estimated by an amount 0.09 .
Figures 1, 2 and 3 illustrate the pattern of actual survival chance in terms of the data captured for placebo, pyridoxine drug and thiotepa drug groups. Note that one outlier case (patient \#15) is present in the placebo group. In addition, it is notable that the trend for the pyridoxine group is a reversed direction compared to the other two groups; patients in the pyridoxine drug group display an upward curve while the placebo group and the thiotepa drug group have downward curves.

\section{Conclusion}

If other predictor variables are available, a logistic regression can be built for patients. In addition, the more and less important predictors can be identified based on the estimate of survivability without a tumor recurrence in the next 12 months.

\section{References}

Andrews, D., \& Herzberg, A. (1990). Data: A collection of problems from many fields for the student and research worker, Berlin: Springer Verlag.

David, H. (2005). Order Statistics. New York, NY: John Wiley and Sons.

Zelen, M., \& Feinlieb, M. (1969). On the theory of screening for chronic diseases. Biometrics, 56. 601-614.

Table 1A: Recurrence Times (in Months) of Tumor Placebo Patients

\begin{tabular}{|c|c|c|c|c|c|c|c|c|c|c|c|c|c|c|}
\hline ID & $1^{\text {st }}$ & $2^{\text {nd }}$ & $3^{\text {rd }}$ & $4^{\text {th }}$ & $5^{\text {th }}$ & $6^{\text {th }}$ & $7^{\text {th }}$ & $8^{\text {th }}$ & $9^{\text {th }}$ & $t_{(1)}$ & $\bar{t}$ & $s_{t}^{2}$ & $\begin{array}{c}\text { Captured Survivability } \\
\text { in 12 Months }\end{array}$ & Cofactor \\
\hline 13 & 3 & 13 & 7 & & & & & & & 3 & 7.7 & 25 & 0.71 & 0.03 \\
\hline 15 & 7 & 3 & 6 & 8 & & & & & & 3 & 6 & 4.67 & 0.03 & 0.15 \\
\hline 16 & 3 & 12 & 10 & & & & & & & 3 & 8.33 & 22.3 & 0.65 & 0.05 \\
\hline 24 & 28 & 2 & & & & & & & & 2 & 15 & 338 & 0.98 & 0.003 \\
\hline 34 & 16 & 3 & 4 & 5 & 6 & 5 & 6 & & & 3 & 6.42 & 18.95 & 0.66 & 0.04 \\
\hline 44 & 3 & 12 & 31 & 5 & 2 & & & & & 3 & 10.6 & 145.3 & 0.96 & 0.005 \\
\hline 48 & 2 & 6 & 4 & 1 & 4 & 4 & 12 & 16 & 15 & 1 & 7,2 & 34.44 & 0.81 & 0.02 \\
\hline
\end{tabular}


TWELVE MONTH TUMOR RECURRENCE: A PROBABILISTIC WARNING

Table 1B: Parameter Estimates of Tumor Placebo Patients

\begin{tabular}{|c|c|c|c|c|c|c|c|c|}
\hline ID & $\hat{\phi}$ & $\theta<(.) \beta$ & $\hat{v}$ & $\begin{array}{c}\text { Restriction } \\
\text { Level }\end{array}$ & $\begin{array}{c}\text { Location } \\
\text { Shift }\end{array}$ & $\begin{array}{c}\text { Scale } \\
\text { Shift }\end{array}$ & $\begin{array}{c}\text { Actual } \\
\text { Chance of } \\
\text { Safe 12 } \\
\text { Months }\end{array}$ & $\begin{array}{c}\text { Overestimated } \\
\text { Proportion in the Chance } \\
\text { of Safe 12 Months in the } \\
\text { Length Biased Data }\end{array}$ \\
\hline 13 & 0.53 & $(2.140$ & 3 & 4.58 & 19.2 & 20.2 & 0.03 & 0.09 \\
\hline 15 & 84.46 & $(39.38)$ & 3 & 3.02 & 4.09 & 5.09 & 0.02 & 0.95 \\
\hline 16 & 0.84 & $(2.23)$ & 3 & 3.46 & 13.11 & 14.11 & 0.04 & 0.14 \\
\hline 24 & 0.03 & $(2.00)$ & 2 & Infinity & 270.69 & 271.69 & 0.003 & 0.004 \\
\hline 34 & 0.58 & $(2.18)$ & 3 & 8.73 & 18.16 & 19.16 & 0.03 & 0.11 \\
\hline 44 & 0.06 & $(2.00)$ & 3 & 85.69 & 154.9 & 155.9 & 0.006 & 0.008 \\
\hline 48 & 0.29 & $(2.07)$ & 1 & 3.64 & 40.3 & 41.35 & 0.02 & 0.03 \\
\hline
\end{tabular}

Table 2A: Recurrence Times (in Months) of Tumor Patients Treated with Pyridoxine Drug

\begin{tabular}{|c|c|c|c|c|c|c|c|c|c|c|c|c|c|c|}
\hline ID & $1^{\text {st }}$ & $2^{\text {nd }}$ & $3^{\text {rd }}$ & $4^{\text {th }}$ & $5^{\text {th }}$ & $6^{\text {th }}$ & $7^{\text {th }}$ & $8^{\text {th }}$ & $9^{\text {th }}$ & $t_{(1)}$ & $\bar{t}$ & $s_{t}^{2}$ & $\begin{array}{c}\text { Captured Survivability in 12 } \\
\text { Months }\end{array}$ & Cofactor \\
\hline 51 & 3 & 1 & & & & & & & & 1 & 2 & 2 & 0.007 & 0.06 \\
\hline 64 & 3 & 7 & 12 & 4 & 8 & & & & & 3 & 6.8 & 12.7 & 0.46 & 0.07 \\
\hline 67 & 3 & 4 & 5 & 4 & 3 & 9 & 6 & 2 & 3 & 2 & 4.33 & 4.5 & 0.08 & 0.10 \\
\hline 70 & 2 & 4 & 4 & 6 & 7 & 4 & 9 & 3 & 3 & 2 & 4,67 & 5 & 0.10 & 0.10 \\
\hline
\end{tabular}

Table 2B: Parameter Estimates of Tumor Patients Treated with Pyridoxine Drug

\begin{tabular}{|c|c|c|c|c|c|c|c|c|}
\hline ID & $\hat{\phi}$ & $\theta<(.) \beta$ & $t_{(1)}$ & $\begin{array}{c}\text { Restriction } \\
\text { Level }\end{array}$ & $\begin{array}{c}\text { Location } \\
\text { Shift }\end{array}$ & $\begin{array}{c}\text { Scale } \\
\text { Shift }\end{array}$ & $\begin{array}{c}\text { Actual Chance } \\
\text { of Safe 12 } \\
\text { Months }\end{array}$ & $\begin{array}{c}\text { Overestimated Proportion } \\
\text { in the Chance of Safe 12 } \\
\text { Months in the Length } \\
\text { Biased Data }\end{array}$ \\
\hline 51 & 6 & 8 & 1 & Infinity & 12.83 & 13.83 & 0.0006 & 0.52 \\
\hline 64 & 1.52 & 2.52 & 3 & 3.67 & 9.03 & 10.03 & 0.05 & 0.25 \\
\hline 67 & 5.87 & 5.27 & 2 & 3.55 & 7.29 & 8.29 & 0.01 & 0.55 \\
\hline 70 & 5.38 & 4.81 & 2 & 3.31 & 7.08 & 8.08 & 0.01 & 0.52 \\
\hline
\end{tabular}

Table 3A: Recurrence Times (in Months) of Tumor Patients Treated with Thiotepa Drug

\begin{tabular}{|c|c|c|c|c|c|c|c|c|c|}
\hline ID & $1^{\text {st }}$ & $2^{\text {nd }}$ & $3^{\text {rd }}$ & $4^{\text {th }}$ & $t_{(1)}$ & $\bar{t}$ & $s_{t}^{2}$ & $\begin{array}{c}\text { Captured Survivability in } \\
12 \text { Months }\end{array}$ & Cofactor \\
\hline 89 & 18 & 0 & & & 0 & 13.3 & 40.5 & 0.97 & 0.003 \\
\hline 104 & 24 & 2 & 3 & 11 & 2 & 10 & 103.3 & 0.94 & 0.007 \\
\hline
\end{tabular}


SHANMUGAM

Table 3B: Parameter Estimates of Tumor Patients Treated with Thiotepa Drug

\begin{tabular}{|c|c|c|c|c|c|c|c|c|}
\hline ID & $\hat{\phi}$ & $\theta<(.) \beta$ & $t_{(1)}$ & $\begin{array}{c}\text { Restriction } \\
\text { Level }\end{array}$ & $\begin{array}{c}\text { Location } \\
\text { Shift }\end{array}$ & $\begin{array}{c}\text { Scale } \\
\text { Shift }\end{array}$ & $\begin{array}{c}\text { Actual Chance } \\
\text { of Safe 12 } \\
\text { Months }\end{array}$ & $\begin{array}{c}\text { Overestimated } \\
\text { Proportion in the Chance } \\
\text { of Safe 12 Months in the } \\
\text { Length Biased Data }\end{array}$ \\
\hline 89 & 0.04 & 2.00 & 0 & infinity & 288 & 289 & 0.003 & 0.003 \\
\hline 104 & 0.09 & 2.01 & 2 & 8.78 & 105.5 & 106.5 & 0.008 & 0.01 \\
\hline
\end{tabular}

Figure 1: Actual Survival Chance in Terms of Captured Survival Chance for Placebo Group

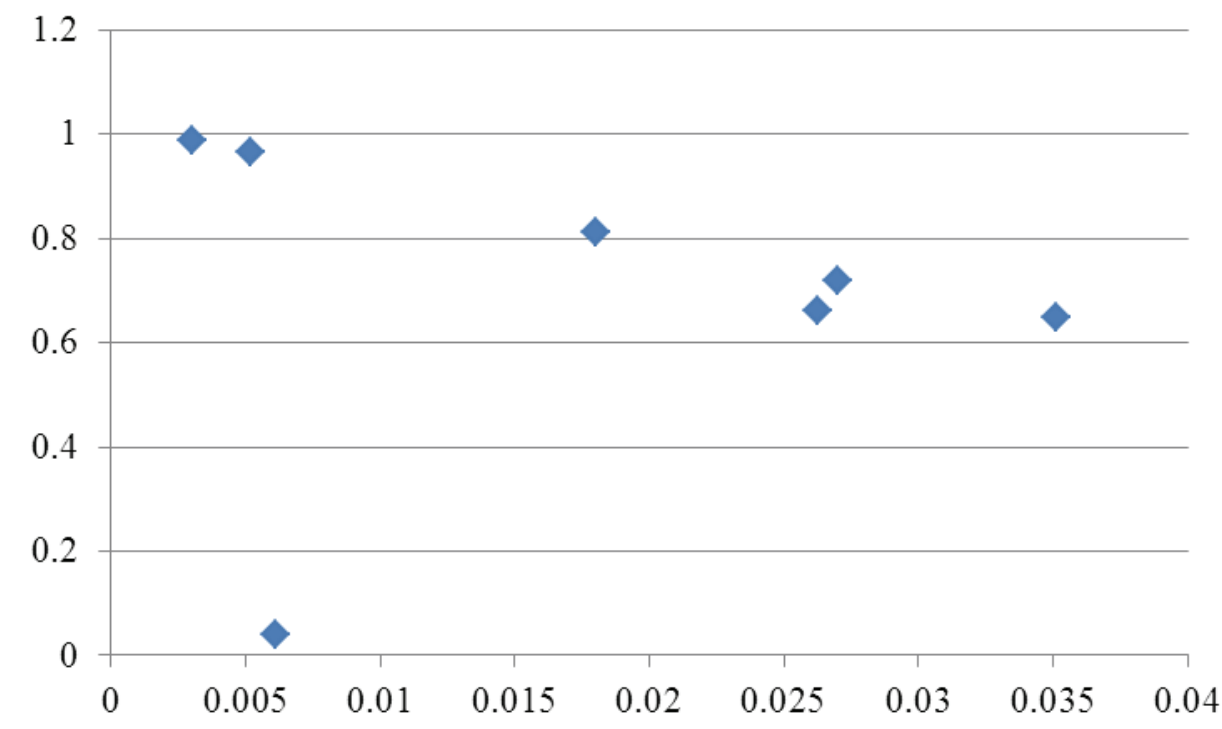

Figure 2: Actual Survival Chance in Terms of Captured Survival Chance for Pyridoxine Drug Group

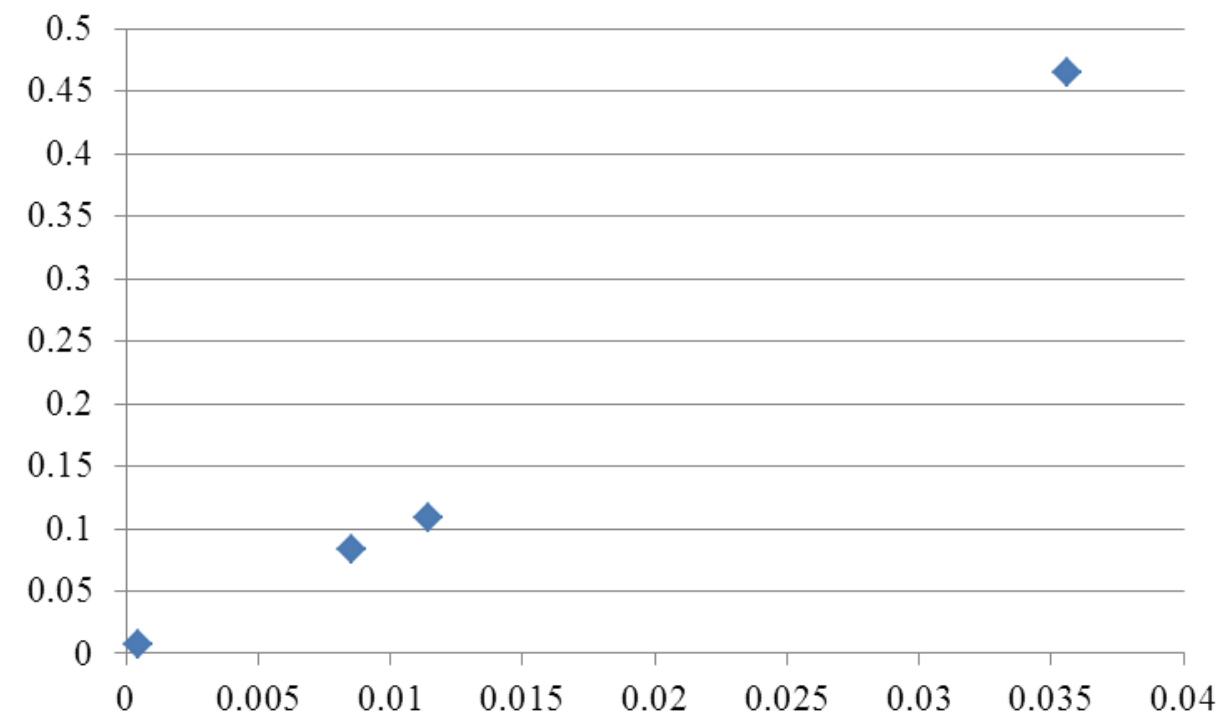


TWELVE MONTH TUMOR RECURRENCE: A PROBABILISTIC WARNING

Figure 3: Actual Survival Chance in Terms of Captured Survival Chance for Thiotepa Drug Group

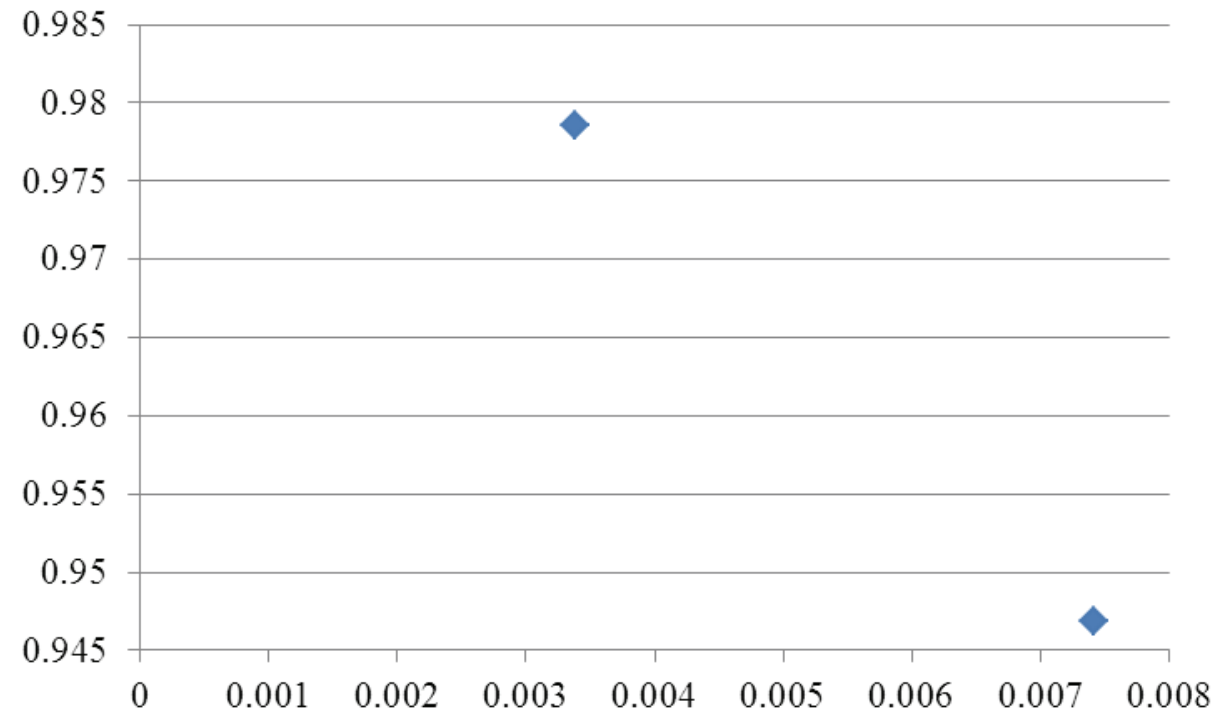

